\title{
CORRELATION OF RENAL FUNCTION TESTS WITH EARLY ONSET NEONATAL SEPSIS.
}

1. MBBS, FCPS (Paeds Med) Senior Registrar Paediatric Medicine Services Hospital / Services Institute of Medical Sciences Lahore.

2. MBBS, M.Phil (Biochem)

Assistant Professor Biochemistry Fatima Memorial College of Medicine and Dentistry Lahore.

3. MBBS, FCPS (Paeds Med)

Associate Professor Paediatric Medicine

Allama Iqbal Medical College Lahore/Jinnah Hospital Lahore.

4. MBBS, FCPS (Haematology)

Assistant Professor Hematology

Services Institute of Medical Sciences Lahore.

5. MBBS, M.Phil (Biochem) Assistant Professor Biochemistry Fatima Memorial College of Medicine and Dentistry Lahore.

6. MBBS, M.Phil (Biochem) Demonstrator Biochemistry Ameer-ud-din Medical College Lahore.

Correspondence Address:

Dr. Amna latidar,

House No. 519, Block-L,

Phase 5 DHA Lahore.

amnaiqtidar@yahoo.com

Article received on:

22/04/2019

Accepted for publication:

25/06/2019
Amna Iqtidar ${ }^{1}$, Imran $\mathrm{Ali}^{2}$, Aamer Naseer ${ }^{3}$, Fouzia Aamer ${ }^{4}$, Kiran Namoos ${ }^{5}$, Haleema Sajid ${ }^{6}$

ABSTRACT: Early onset neonatal sepsis is invariably very common and serious problem worldwide, especially it is one of the important etiological factor for deaths of neonates in Pakistan. Acute renal failure is frequently seen in neonates with sepsis. Objectives: The aim of present study was to determine the correlation of renal function tests (Blood Urea and creatinine) with early onset neonatal sepsis. Study Design: Descriptive study. Setting: Department of Paediatric Medicine Sir Ganga Ram hospital, Lahore. Period: Six months from 20th March to 20th September 2018. Material \& Methods: Total 300 cases of neonatal sepsis with acute renal failure were included in this study after taking informed consent from the parents. Cases selection was done with help of a predefined inclusion and exclusion criteria. Daily blood urea and serum creatinine were calculated from birth to first 7 days of life. If any of blood urea or serum creatinine was deranged, the neonate was labelled as having acute renal failure. Data was entered and analysed using SPSS software version 21. Results: Mean age of all cases was $2.82 \pm 1.56$ days. The minimum and maximum age limits of the neonates were 1 and 7 days respectively. Gender distribution of neonate showed that $57 \%$ of the neonates were male and $43 \%$ were females. At the $2^{\text {nd }}$ day of life, mean serum creatinine level was $1.12 \pm 0.39$, at $3^{\text {rd }}$ day $1.19 \pm 0.51$, at $4^{\text {th }}$ day $1.41 \pm 0.38$, at $5^{\text {th }}$ day $1.33 \pm 0.39$, at $6^{\text {th }}$ day $1.19 \pm 0.39$, and at $7^{\text {th }}$ day mean serum creatinine level was $1.09 \pm 0.31$ respectively. At $2^{\text {nd }}$ day of birth mean blood urea was $54.82 \pm 34.77$, at $3^{\text {rd }}$ day $59.50 \pm 28.22$ at $4^{\text {th }}$ day $74.94 \pm 30.37$, at $5^{\text {th }}$ day $67.09 \pm 26.94$, at $6^{\text {th }}$ day $56.09 \pm 25.76$, at $7^{\text {th }}$ day mean blood urea level was $47.66 \pm 22.47$ respectively. Frequency of acute renal failure was observed in $28.3 \%$ of the neonates while the remaining $71.7 \%$ of neonates did not suffer from acute renal failure. Conclusion: Early onset neonatal sepsis contributes significantly to development of acute renal failure in neonates.

Key words: $\quad$ Acute Renal Failure, Neonates, Renal function tests, Sepsis

Article Citation: lqtidar A, Ali I, Naseer A, Aamer F, Namoos K, Sajid H. Correlation of renal function tests with early onset neonatal sepsis. Professional Med J 2020; 27(2):317-323. DOI: 10.29309/TPMJ/2020.27.2.3581

\section{INTRODUCTION}

The etiological factors of deaths in neonatal phase in Pakistan are poorly assessed though major constituents observed are birth asphyxia, prematurity, sepsis and malformation. ${ }^{1,2}$ Neonatal sepsis is a serious clinical problem seen across the globe. The occurrence of neonatal sepsis is around 1-10/1000 live births in developed countries however it is three times more common in Pakistan. ${ }^{3}$ The definition of sepsis is coined as an infection which is complicated by dysfunction of one or more body organs. The dysfunction of an organ is evaluated on the basis of SOFA score (Sequential Organ Failure Assessment score) which rises by two or more points. ${ }^{4}$
Neonatal sepsis is categorized clinically into two types, early and late onset neonatal sepsis. Early onset sepsis is defined as sepsis in neonates aged upto 7 days. ${ }^{5}$ The Glomerular filtration rate of the kidneys in new borns is reported to be low and is about $1 \mathrm{ml} / \mathrm{kg} /$ minute of body weight and is balanced by vasoconstriction and vasodilation factors. The kidneys of the neonates have very little potentiality to subsist with any endogenous or exogenous factors of stress. ${ }^{6}$

Acute kidney failure is a wide-spread clinical entity in neonates with sepsis. ${ }^{7}$ Plasma creatinine levels of new born infant reflects creatinine level of the mother. It gradually drops in first 2 weeks of newborn life from a mean value of $1.1 \mathrm{mg} / \mathrm{dl}$ 
(term baby) or $1.3 \mathrm{mg} / \mathrm{dl}$ (Preterm baby) to 0.4 $\mathrm{mg} / \mathrm{dl}$. However in babies with acute renal failure, plasma creatinine level starts rising. About $1 / 3^{\text {rd }}$ of the neonates have normal urine output in acute kidney failure while some have low urine output in the absence of acute renal failure. The most frequently used reliable indicator of kidney function is serum creatinine in the neonate. Acute renal failure in the neonates is determined by the rise in plasma creatinine level above $1.5 \mathrm{mg} / \mathrm{dl}$ at least for 1 to 2 days. $^{8}$

In a study conducted by Mortazavi et al in Iran, acute kidney failure was observed in 28 (32.9\%) neonates having sepsis out of $85 . .^{9}$ This study can help us in calculating the frequency of acute kidney failure connected with neonatal sepsis by serial evaluation of RFTs as this customary is not common in our clinical routine and thus renal complication is not given due attention. No local work is accessible about the immensity of acute renal failure in neonates of our population having early onset neonatal sepsis. Neonatal sepsis is a typical finding in Pakistan causing high mortality and morbidity rates in our piece of land. Through our study we will try to assess the actual frequency of acute renal failure seen in neonatal sepsis. High rates of mortality and morbidity due to this treatable kidney complication of sepsis can hence be prevented by incorporating serial evaluation of the renal function tests in routine clinical protocols.

\section{STUDY MATERIAL AND METHODS Study Design}

Descriptive study

\section{Sample Size and Study Settings}

Study work was performed on 300 patients in the department of Paediatric medicine, Sir Ganga Ram Hospital Lahore, Pakistan. Sample size is measured with $6 \%$ error margin, 95\% confidence interval, and taking expected percentage of acute renal failure (ARF) as $32.9 \%$ in neonates with early-onset neonatal sepsis. ${ }^{9}$

\section{Study Duration}

The study was completed in six months from 20th March to 20th September 2018.

\section{Inclusion Criteria}

1. Neonates with positive septic screening

2. Term babies with 37 weeks gestational record

3. Neonates with normal birth weight of $2.5 \mathrm{~kg}$ or more

\section{Exclusion Criteria}

1. Babies with congenital abnormalities of kidneys or urinary tract or any other congenital anomalies ( confirmed by prenatal USG)

2. Babies who received aminoglycosides

3. Maternal history of kidney dysfunction

4. Acute kidney injury postoperative

\section{Sampling Method}

Non-probability, purposive sampling.

\section{Laboratory Analysis}

300 septic neonates meeting our inclusion/ exclusion criteria admitted in neonatal unit, were registered in the study. Informed consent was obtained from parents before baby registration. The registered neonates were catheterized to measure the urine output. Septicemia was clinically speculated in neonates having fever, vomiting episodes, feeding difficulty, irritability and lethargy. Confirmation of septicemia was done on positive culture of blood in lab tests. Proper sterile environment and skin disinfection was made sure before performing blood culture. Serum creatinine and blood urea levels were evaluated from birth to first seven days of neonatal life. If values of the renal function tests (serum creatinine or blood urea) were found deranged in any neonate then we will label it as having acute renal failure.

The diagnosis of acute renal failure is based on the criteria defined by Acute Kidney Injury Network (AKIN) group as follows ${ }^{10}$ :

Stage 0: No change or rise in serum creatinine $<0.3 \mathrm{mg} / \mathrm{dl}$

Stage I: Rise in serum creatinine $>0.3 \mathrm{mg} / \mathrm{dl}$ or Serum Creatinine > $150-200 \%$ from baseline

Stage II: Serum Creatinine > $200 \%-300 \%$ from baseline

Stage III: Serum Creatinine of $>300 \%$ from 
baseline

Serum Creatinine concentration was ignored in the first 24 hours of life, as it reflected the maternal value.

Bias was addressed properly by having renal investigations from single lab and effect modifiers were addressed through the help of exclusion criteria.

\section{Statistical Analysis}

The statistical data was entered and analyzed with the help of SPSS software version 21. The percentages and frequency were measured for variables like gender and ARF. Mean along with standard deviations (mean \pm SD) was analyzed for quantitative variables like serum creatinine, age blood urea. Data was then displayed theoretically as frequency tables, charts and graphs.

\section{RESULTS}

The current study conducted in neonatal unit, department of pediatric medicine Sir Ganga Ram Hospital Lahore, comprises of 300 neonates fulfilling our inclusion and exclusion parameter. The mean age observed in all neonates was $2.82 \pm 1.56$ days. The minimum and maximum neonatal ages were one and seven days respectively and the mean neonatal age of male and female babies were $2.83 \pm 1.40$ and $2.82 \pm 1.80$ days respectively. (Table-I) Gender distribution of neonates depicts that $57 \%$ of the children in our study were male and $43 \%$ of the children enrolled were females. (Fiqure-1).

\section{Male 171 Famale 129}

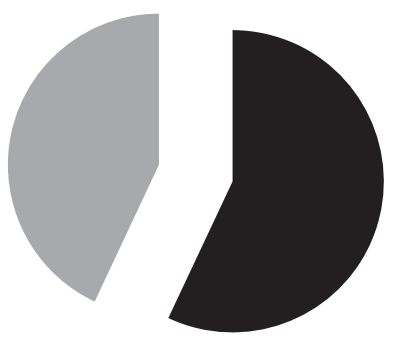

Figure-1. Gender distribution of patients

The serum creatinine levels were measured on regular basis for the first 7 days of life. The mean serum creatinine levels were $1.12 \pm 0.39$, $1.19 \pm 0.51,1.41 \pm 0.38,1.33 \pm 0.39, \quad 1.19 \pm 0.38$ and $1.09 \pm 0.31$ on $2^{\text {nd }}, 3^{\text {rd }}, 4^{\text {th }}, 5^{\text {th }}, 6^{\text {th }}$, and $7^{\text {th }}$ day respectively. (Table-II) Daily blood urea was evaluated till 7 days. The mean blood urea levels were 54.82 $\pm 34.77,59.50 \pm 28.22,74.94 \pm 30.37$, $67.09 \pm 26.94, \quad 56.09 \pm 25.76 \quad 47.66 \pm 22.47$ on $2^{\text {nd }}, 3^{\text {rd }}, 4^{\text {th }}, 5^{\text {th }}, 6^{\text {th }}$, and $7^{\text {th }}$ day respectively. (TableIII)

Renal function tests derangements were observed in $28.3 \%$ (85 out of 300 ) of the neonates leading to acute renal failure in these neonates. Among these 85 neonates having acute renal failure 50 were found to be male and the remaining 35 were female neonates. (Table: 4).

\begin{tabular}{|l|c|c|}
\hline \multicolumn{1}{|c|}{ Gender } & N & Age(Mean+- SD) \\
\hline Male & 171 & $2.83+.1 .4$ \\
\hline Female & 129 & $2.82+-1.8$ \\
\hline Total & 300 & $2.82+\_1.56$ \\
\hline
\end{tabular}

Table-I. Age and gender distribution of cases:

\begin{tabular}{|c|c|c|c|}
\hline & $\begin{array}{l}\text { Acute Renal } \\
\text { Failure }\end{array}$ & Mean & SD \\
\hline \multirow{3}{*}{$\begin{array}{l}\text { Day } 2 \\
\text { Serum Creatinine (mg/dl) }\end{array}$} & Yes & 1.14 & 0.40 \\
\hline & No & 0.82 & 0.15 \\
\hline & Total & 1.12 & 0.39 \\
\hline \multirow{3}{*}{$\begin{array}{l}\text { Day } 3 \\
\text { Serum Creatinine (mg/dl) }\end{array}$} & Yes & 1.24 & 0.51 \\
\hline & No & 0.65 & 0.10 \\
\hline & Total & 1.19 & 0.51 \\
\hline \multirow{3}{*}{$\begin{array}{l}\text { Day } 4 \\
\text { Serum Creatinine (mg/dl) }\end{array}$} & Yes & 1.45 & 0.38 \\
\hline & No & 1.00 & 0.16 \\
\hline & Total & 1.41 & 0.38 \\
\hline \multirow{3}{*}{$\begin{array}{l}\text { Day } 5 \\
\text { Serum Creatinine (mg/dl) }\end{array}$} & Yes & 1.36 & 0.38 \\
\hline & No & 0.92 & 0.25 \\
\hline & Total & 1.33 & 0.39 \\
\hline \multirow{3}{*}{$\begin{array}{l}\text { Day } 6 \\
\text { Serum Creatinine (mg/dl) }\end{array}$} & Yes & 1.22 & 0.36 \\
\hline & No & 0.82 & 0.42 \\
\hline & Total & 1.19 & 0.38 \\
\hline \multirow{3}{*}{$\begin{array}{l}\text { Day } 7 \\
\text { Serum Creatinine (mg/dl) }\end{array}$} & Yes & 1.11 & 0.31 \\
\hline & No & 0.87 & 0.15 \\
\hline & Total & 1.09 & 0.31 \\
\hline
\end{tabular}

Table-II. Serum creatinine on different days in neonates with \& without acute renal failure 


\begin{tabular}{|l|c|c|c|}
\hline & $\begin{array}{c}\text { Acute Renal } \\
\text { Failure }\end{array}$ & Mean & SD \\
\hline \multirow{2}{*}{ Day 2 } & Yes & 58.00 & 34.92 \\
\hline Blood Urea (mg/dl) & No & 25.60 & 14.31 \\
\hline & Total & 54.82 & 34.77 \\
\hline \multirow{2}{*}{ Day 3 } & Yes & 62.82 & 27.64 \\
\hline Blood Urea (mg/dl) & No & 29.00 & 8.48 \\
\hline & Total & 59.50 & 28.22 \\
\hline Day 4 & Yes & 79.84 & 27.74 \\
\hline Blood Urea (mg/dl) & No & 29.80 & 6.94 \\
\hline & Total & 74.94 & 30.37 \\
\hline Day 5 & Yes & 70.54 & 26.09 \\
\hline Blood Urea (mg/dl) & No & 35.40 & 4.56 \\
\hline & Total & 67.09 & 26.94 \\
\hline \multirow{2}{*}{ DAY 6 } & Yes & 57.93 & 26.49 \\
\hline Blood Urea (mg/dl) & No & 39.20 & 1.09 \\
\hline & Total & 56.09 & 25.76 \\
\hline Day 7 & Yes & 48.58 & 23.49 \\
\hline Blood Urea (mg/dl) & No & 39.20 & 1.78 \\
\hline & Total & 47.66 & 22.47 \\
\hline
\end{tabular}

Table-III. Blood urea on different days in neonates with \& without acute renal failure

\begin{tabular}{|l|l|c|c|c|}
\hline \multirow{2}{*}{ Gender } & \multicolumn{4}{|c|}{ Acute Renal Failure } \\
\hline \multirow{2}{*}{ Total } & Male & Yes & No & Total \\
\cline { 2 - 6 } & Female & $35(29.2 \%)$ & $121(70.8 \%)$ & $171(57 \%)$ \\
\hline \multirow{2}{*}{ Tabl.1\%) } & $94(72.9 \%)$ & $129(43 \%)$ \\
\hline
\end{tabular}

Table-IV. Frequency of acute renal failure in relation to gender of the patients

\section{DISCUSSION}

Acute renal failure (ARF) is a common morbidity observed in sick neonates. Although our understanding of neonatal ARF is increased, still herculean amount of work is required to enhance our capacity to diagnose correctly all neonates having ARF.

The acute renal failure in neonates is multifactorial. The most well recognized and established causes of ARF are asphyxia, urogenital anomalies and respiratory distress syndrome (RDS). Another etiological factor is sepsis which is reported as leading cause of ARF.8,9

The kidneys in neonatal phase are especially prone to develop hypoperfusion as the vascular resistance of kidneys and plasma renin levels are on higher side. Due to these and other factors blood flow to kidneys is relatively more decreased in neonates. Moreover during the neonatal life, the renin-angiotensin mechanism is essential for normal kidney blood flow and development. Furthermore vasoconstriction at the afferent and more markedly at efferent arterioles is observed due to effects of effector molecule Angiotensin II, of the renin-angiotensin system. Some other mediators like Prostaglandins have an important role and lead to afferent arteriole dilatation. The impact of these systems is more pronounced during acute kidney injury where these systems must be suppressed by medication. ${ }^{11}$

Many foreign studies describe that the prevalence of acute renal failure is more common in males as compared to female neonates (male to female ratio $3: 1$ ). That means that the precipitating factors of acute renal failure like respiratory distress and sepsis are more in males as compared to female neonates. $^{12}$

Our study showed that acute renal failure was more common in males as compared to females which is in agreement with previous studies showing more male prevalence of acute renal failure in septic neonates.

Azat in his study in 2011 reported about 50 cases which were diagnosed as having acute renal failure out of 2500 neonates admitted in hospital $(2 \%)$. The male to female ratio in acute renal failure patients was $3.16: 1 .^{13}$

Another study by Gharehbaghi revealed $85(2.83 \%)$ neonates were diagnosed with acute renal failure out of 3000 registered neonates with male to female ratio of $2.03: 1 .{ }^{8}$

In our study there were $85(28.3 \%)$ cases diagnosed with acute renal failure among 300 septic neonates. Gender distribution among cases of acute renal failure reveals that renal failure was greater in males i.e. $29.2 \%$ as compared to that of females. (27.1\%). This is in line with previous studies done for gender distribution in acute renal 
failure among neonates showing male prevalence of ARF.

Sepsis can result in renal failure through various mechanisms. Theetiologicalfactorsofacutekidney injury are multifold. Various mechanisms including ischemic/hypoxic, nephrotoxic, complement and coagulation activation, free radical formation, Pro-inflammatory cytokine production, cell activation (neutrophils, platelets, macrophages and endothelial cells), vasodilation induced glomerular hypo-perfusion, an abnormal blood flow within the peri-tubular capillary network and inflammatory insults contribute to acute kidney injury in sepsis. ${ }^{14}$

Sepsis presents with ARF in most of the cases. Neonatal kidneys are very vulnerable, and neonates with sepsis can go into renal failure at the start. Delayed reporting by parents is another reason for poor outcome. Important information can be obtained by comparing neonate with and without acute renal failure. In septic infants and neonates, low birth weight is an important triggering factor in causing acute renal failure. Disseminated intravascular coagulation and shock are the two parameters which are more prevalent in neonates suffering from acute renal failure. Oliguric and non-oliguric renal failure both are reported in neonatal septicemia. The oliguric renal failure may be seen in $15-93 \%$ of neonates with septicemia. ${ }^{15}$

Neonatal sepsis can lead to high frequency of mortality and morbidity. Many factors contribute to increase prevalence of mortality in septic neonates. Some important factors are low birth weight, low gestational age, mechanical ventilation and parenteral nutrition. ${ }^{16}$

To the best of our knowledge, no such study has been published in our working set up till date which associates neonatal sepsis with ARF. In a study done in India by Kapoor et al in 2013 on 456 neonates, 44 (9.6\%) neonates were found to be having acute renal failure (12 females and 32 males). Oliguria was found in 29 out of 44 ARF neonates. The commonest cause of acute renal failure in these 44 neonates was neonatal sepsis. The other contributing factors for ARF were reported as perinatal asphyxia, genito-urinary anomalies and respiratory distress syndrome. Acute renal failure at admission was found in 37 out of these 44 neonates. The mortality rate in their study was $15.9 \%$ (7/44). Out of 44 septic neonates, 37 patients (84\%) had complete recovery followed by discharge. Disseminated intravascular coagulation (DIC), shock, mechanical ventilation and oliguria were found to be important mortality predictors in neonates with acute renal failure. ${ }^{17}$

In another study done by Patel et al in 2016 in India showed $60 \%$ (52 out of 87 neonates) mortality in critically ill neonates. Sepsis was reported to be most common cause of ARF in their study. ${ }^{18}$

In a study done by Momtaz et al in Besat hospital Iran revealed that out of 49 cases of acute kidney injury, the incidence of oliguria was reported to be $77.5 \%$ (38 out of 49). Sepsis was the most reported predisposing factor for acute kidney injury in their study. ${ }^{19}$

In our study frequency of acute renal failure was $28.3 \%$ in neonates with sepsis. In a study done by Mathur et al in India, frequency of acute renal failure was reported to be $26 \%$ (52 out of 200 septic neonates)..$^{20}$ This is in line with our study but percentage of ARF is slightly lower than our results which may be due to lower number of patients in their study.

In another study done by Durga et al in 2017, 24\% (12 out of 50) septic neonates had developed acute renal injury and mortality rate was reported to be $75 \%$ in their study. Total number of septic neonates enrolled were less (only 50) as compared to our study. ${ }^{21}$

Gaurav et al in their study in India showed $21.49 \%$ (34 out of 107) septic neonates developed acute renal failure. This is slightly lower percentage than our value as number of patients in their study was less as compared to our study. ${ }^{22}$

Gupta et al in their study in India revealed $23 \%$ neonates (16 out of 70 ) developed acute renal 
failure. This is also in line with our study. Total number of septic neonates enrolled were less as compared to our 300 septic neonatal cases. ${ }^{23}$

In another study done by Pradhan et al, $28 \%$ of septic neonates had developed acute renal failure which is in line with our study. ${ }^{24}$

In a study done in Cairo Egypt by Salah et al, acute renal failure complicating neonatal sepsis occurred in $31.6 \%$ (79 out of 250 ) cases. This, in contrast to our study, is slightly higher than our results. This may be due to the fact that most of the neonates who developed acute kidney injury were preterm (35 cases) in their study. ${ }^{25}$

Our study reveals that acute renal failure in very important entity in septic neonates which can lead to high mortality if it is not diagnosed and managed promptly. ARF can lead to decreased urine output and renal failure can be easily overlooked if serum creatinine is not monitored on routine basis.

The causative factors for acute kidney injury in neonates are multifold. The incidence of acute renal failure in neonates may be caused by sepsis, nephrotoxic drug use, asphyxia, and dehydration. ${ }^{26}$

\section{CONCLUSION}

The present study observations clearly reveal that ARF is a very common entity among septic neonates. In this study $28.3 \%$ of the cases had suffered from ARF who were admitted in Neonatal ICU in Sir Ganga Ram Hospital, having positive septic screening. Physicians can play a critical role in recognizing early ARF, preventing iatrogenic injury, and reversing the course of ARF in neonates with sepsis.

\section{LIMITATION OF THE STUDY}

1. This is a single hospital NICU study and does not reflect prevalence in a community.

11. Additional large scale prospective cohort studies should be done to determine acute renal failure percentage in septic neonates.

\section{RECOMMENDATION}

It is highly recommended that renal function tests should be done in all neonates with positive septic screening and other physical signs and symptoms. This can prevent high mortality and morbidity rates observed in septic neonates due to acute renal failure.

\section{ACKNOWLEDGMENTS}

The authors acknowledge Prof. Dr. Ayesha Arif for providing supervision and the working facilities for this project. The authors are also thankful to all the respected teachers Pediatric medicine department Sir Ganga Ram Hospital Lahore for their guidance and logistic support. The authors are also grateful to Dr. Mehak Zahra for providing help in statistical analysis of the data.

\section{Copyright $\subset 25$ June, 2019.}

\section{REFERENCES}

1. Sankar MJ, Natarajan CK, Das RR, Agarwal R, Chandrasekaran A, Paul VK. When do newborns die? A systematic review of timing of overall and causespecific neonatal deaths in developing countries. J Perinatol. 2016; 36(Suppl 1):S1-S11.

2. Mehmood Z SM. "A survey of infection control practices in Pakistan". APMC 2009; 3(2):129-31.

3. Mehmood A RR, Chughtai $F$ "Frequency of neonatal sepsis in Pakistan." JPMA. 2008(58):237.

4. Singer M, Deutschman CS, Seymour CW, et al. The third international consensus definitions for sepsis and septic shock (sepsis-3) JAMA. 2016; 315(8):801810.

5. Seale AC, Mwaniki M, Newton CR, Berkley JA. Maternal and early onset neonatal bacterial sepsis: burden and strategies for prevention in sub-Saharan Africa. Lancet Infect Dis. 2009; 9(7):428-38.

6. Hoseini R, Otukesh $\mathrm{H}$, Rahimzadeh $\mathrm{N}$, Hoseini S. Glomerular function in neonates. Iran J Kidney Dis. 2012; 6(3):166-72.

7. Fitzgerald JC, Basu RK, Akcan-Arikan A, Izquierdo LM, Pineres Olave BE, Hassinger $A B$ et al. Acute kidney injury in pediatric severe sepsis: An independent risk factor for death and new disability. Crit Care Med. 2016; 44(12):2241-2250.

8. Gharehbaghi M, Peirovifar A. Evaluating causes of acute renal failure in newborn infants. Pakistan journal of medical sciences. $2007 ; 23(6): 877$. 
9. Mortazavi F, Sakha SH, Nejati N. Acute kidney failure in neonatal period. Iranian Journal of Kidney Diseases. 2009; 3(3):136-40.

10. Jetton JG, Askenazi DJ. Update on acute kidney injury in the neonate. Curr Opin Pediatr. 2012; 24(2):191-6.

11. Selewski DT, Charlton JR, Jetton JG, Guillet R, Mhanna MJ, Askenazi DJ et al. Neonatal Acute Kidney Injury. Pediatrics. 2015; 136(2).

12. Airede AK, Bello $M$, Weerasinghe $H$. Acute renal failure in the newborn: Incidence and outcome. Journal of paediatrics and child health. 1997; 33(3):246-9.

13. Azat NFA, abdalmahdi Salih A, Naoom MB. Acute renal failure in neonates. Iraqi postgraduate medical journal. 2011; 10(2).

14. Doi K. Role of kidney injury in sepsis. J Intensive Care. 2016; 4: 17.

15. Nickavar A, Khosravi N, Mazouri A. Predictive factors for acute renal failure in neonates with Septicemi. Arch pediater infect dis. 2017; 5(4).

16. Turhan EE, Gursoy T, Ovalı F. Factors which affect mortality in neonatal sepsis. Turk Pediatri Ars. 2015; 50(3): 170-175.

17. Kapoor K, Jajoo M, Dabas K, Predictors of Mortality in Out Born Neonates with Acute Renal Failure; an Experience of a Single Center. Iran J Pediatr. 2013; 23(3): 321-6.

18. Patel A, Sharma D, Shastri S, Sharma P. Acute renal failure in critically ill newborns increases the risk of death: A prospective observational study from India. J Matern Fetal Neonatal Med. 2016; 29(17):2878-82.
19. Momtaz HE, Sabzehei MK, Rasuli B, Torabian S. The main etiologies of acute kidney injury in the newborns hospitalized in the neonatal intensive care unit. J Clin Neonatol. 2014; 3(2): 99-102.

20. Mathur N, Agarwal HS, Maria A. Acute renal failure in neonatal sepsis. The Indian Journal of Pediatrics. 2006; 73(6):499-502.

21. Durga D, Rudrapp S. Clinical profile and outcome of acute kidney injury in neonatal sepsis in a tertiary care centre. International Journal of Contemporary Pediatrics. Int J Contemp Pediatr. 2017; 4(2):635-44.

22. Jagrawal G, Arora V, Gunawat M, Mali P. Acute renal failure in neonatal septicemia. IJBR.2016; 7(5):260-4.

23. Gupta A, Sethi RS, Chaurasiya OS, Sethi A. Effects of neonatal septicemia on renal function. 2018:11(2):2731.

24. Pradhan SK, Pradeep S, Swain A, Satpathy SK, Behera JN. A study on acute kidney injury (AKI) in neonatal sepsis: IOSR-JMDS. 2014; 13:01-4.

25. Salah MH, Hamdi N, Algayar A, Khashab A. Effect of septicemia on renal performance in neonates. Med $\mathrm{J}$ CarioUniv. 2010; 78:361-7.

26. Pradhan DD, Meher BK, Panda SK, Samal D. Prevalence and factors affecting prognosis in neonates with acute kidney injury in a neonatal intensive care unit. J Clin Neonatol 2018; 7:237-42.

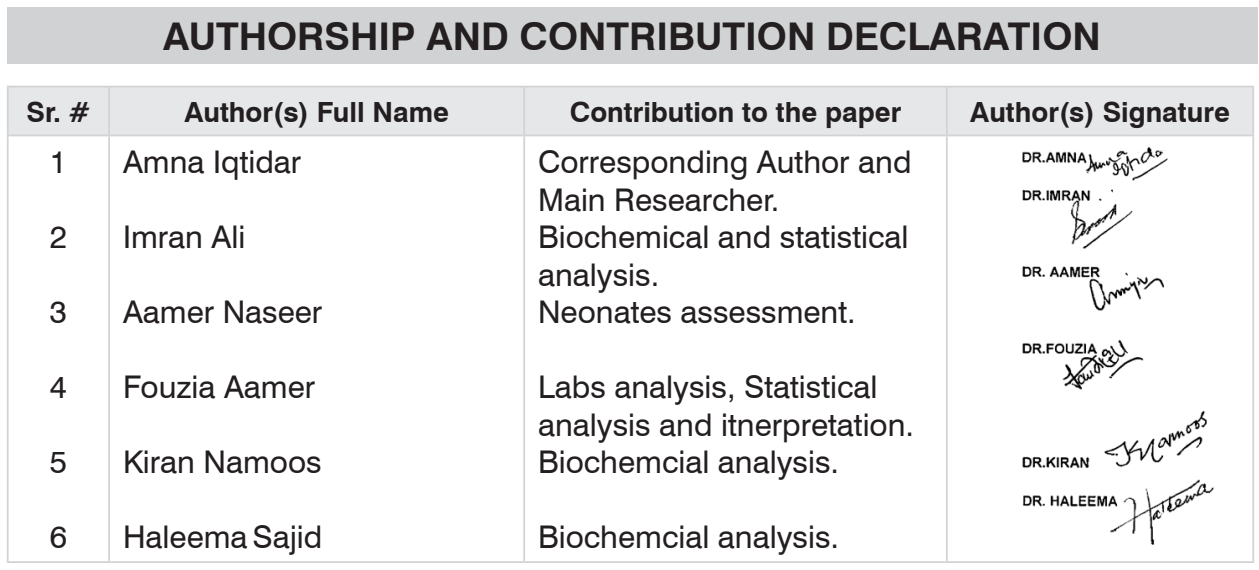

